\title{
STUDI VARIASI WARNA LAMPU TERHADAP LALAT YANG TERPERANGKAP PADA ALAT PEREKAT DI RUMAH PEMOTONGAN AYAM DI MAKASSAR
}

Study of light color variations of flesh trapped on adhesive tools in Chicken cutting house in makassar

Risma Novianti' ${ }^{1}$, Ain Khaer², Budirman ${ }^{3}$

1,2,3 Poltekkes Kemenkes Makassar khaerain@gmail.com

\section{ABSTRACT}

Flies are one of the insects (insects) that play a role in health problems, namely as vectors for disease transmission. The flies' sensitivity to light is in the wavelength range of $245 \mu \mathrm{m}-600 \mu \mathrm{m}$ (green/blue). This study aims to determine the number of flies trapped in the adhesive device with variations in the color of blue, yellow, green, and control lights. The exposure is done in the morning and evening. This type of research is quasi-experimental using physical-mechanical control methods. The results showed that the number of flies trapped in the adhesive device in the morning was 16 in the blue light, 15 in the yellow light, 30 in the green light, and 10 in the control. Meanwhile, the number of flies trapped in the afternoon is 22 in the blue light, 15 in the yellow light, 36 in the green light, and 6 in the control. in the adhesive tool with the addition of a green light which is categorized as very high and the owner of the chicken, the slaughterhouse should pay attention to the cleanliness of the environment. Keywords: Variation of Lamp Color, Flies Density Level, Chicken Slaughterhouse

ABSTRAK

Lalat merupakan salah satu insekta (serangga) yang berperan dalam masalah kesehatan, yaitu sebagai vektor penularan penyakit. Kepekaan lalat terhadap cahaya berada diantara rentang panjang gelombang $245 \mu \mathrm{m}-600 \mu \mathrm{m}$ (hijau/biru). Penelitian ini bertujuan untuk mengetahui jumlah lalat yang terperangkap pada alat perekat dengan variasi warna lampu biru, kuning, hijau dan kontrol. Pemaparan dilakukan pada pagi dan sore hari. Jenis penelitian ini bersifat eksperimen semu dengan menggunakan metode pengendalian fisik-mekanik. Hasil penelitian menunjukkan bahwa jumlah lalat yang terperangkap pada alat perekat di pagi hari yaitu 16 ekor pada lampu warna biru, 15 ekor pada lampu warna kuning, 30 ekor pada lampu warna hijau dan 10 ekor pada kontrol. Sedangkan jumlah lalat yang terperangkap di sore hari yaitu 22 ekor pada lampu warna biru, 15 ekor pada lampu warna kuning, 36 ekor pada lampu warna hijau dan 6 ekor pada kontrol.Kesimpulan yang didapatkan dari penelitian yang telah dilakukan yaitu jumlah lalat yang paling banyak terperangkap di alat perekat dengan penambahan lampu warna hijau yang dikategorikan sangat tinggi dan sebaiknya pemilik pemotongan ayam harus memperhatikan kebersihan lingkungannya.

Kata Kunci : Variasi Warna Lampu, Tingkat Kepadatan Lalat, Rumah Pemotongan Ayam

\section{PENDAHULUAN}

Masalah kesehatan berkaitan dengan populasi lalat umumnya berhubungan dengan unit peternakan dan tempat pembuangan sampah. Seperti yang telah diketahui bahwa lalat merupakan jenis serangga yang mempunyai kemampuan terbang hingga jarak $8 \mathrm{~km}$. Dengan demikian tempat pemotongan ayam dalam radius tersebut sangat rawan terhadap tingkat kepadatan lalat yang tinggi. Kepadatan lalat akan meningkat jika lingkungan di sekitarnya memungkinkan untuk menjadi tempat perindukan lalat. (Sitobang, 2013)

Lalat merupakan salah satu insekta (serangga) yang termasuk ordo diphtera, mempunyai sepasang sayap berbentuk membran. Lalat juga merupakan species yang berperan dalam masalah kesehatan masyarakat, yaitu sebagai vektor penularan penyakit saluran pencernaan seperti diare, kolera, thypus, disentri , dan lain-lain. Pada saat ini dijumpai \pm 60.000 100.000 species lalat, tetapi tidak semua species perlu diawasi karena beberapa diantaranya tidak berbahaya terhadap kesehatan masyarakat. Penularan penyakit dapat terjadi melalui semua bagiandari tubuh lalat seperti : bulu badan, bulu pada anggota gerak, muntahan sama fecesnya. (Nartika Emelia, 2016)

Penyakit diare merupakan penyakit endemis di Indonesia dan juga merupakan penyakit potensi KLB yang sering disertai dengan kematian. Hasil Riskesdas 2013 mengumpulkan informasi insiden diare agar bisa dimanfaatkan program, dan period prevalens diare agar bisa dibandingkan dengan Riskesdas 2007. Period prevalen diare pada Riskesdas $2013(5,2 \%)$ lebih kecil dari Riskesdas 2007 $(7,9 \%)$. Penurunan period prevalen dimungkinkan juga karena waktu pengambilan sampel yang tidak sama antara 2007 dan 2013. Insiden diare yang didiagnosis untuk semua kelompok umur di Sulawesi Selatan adalah 2,8 persen.

Kabupaten/Kota dengan angka kesakitan diare tertinggi (13.689-28.908) yaitu Kabupaten Makassar, Gowa, Bulukumba, Takalar, Pangkep, dan Luwu Utara, sedangkan terendah (2,679-6.398) yaitu Kabupaten Selayar, Sinjai, Maros, Barru, Luwu, Tana Toraja, dan Kota Parepare.

Berdasarkan data Dinas Kesehatan Provinsi Sulawesi Selatan Tahun 2014 perkiraan diare sebanyak 180.570 kasus, adapun diare yang ditangani sebanyak 240.381 kasus $(133,12 \%)$. Dengan kejadian terbesar di Kota Makassar dengan jumlah yang ditangani dilaporkan sebanyak 26.485 kasus dari seluruh jumlah penduduk sebanyak 1.429.242 jiwa. (Profil Dinkes Sulawesi Selatan, 2014). 
Berbagai jenis pengendalian lalat yang telah ada yaitu melalui metode sanitasi, mekanik/fisik, dan kimiawi, untuk meminimalisir dampak negatif penggunaan insektisida, maka perlu dikembangkan metode pengendalian lalat berdasarkan anatomi dan morfologi lalat yang mempengaruhi bionomik lalat.

Lalat mempunyai sistem penglihatan sangat baik, yaitu mata majemuk yang tersusun atas lensa optik banyak sehingga lalat mempunyai sudut pandang lebar. Kepekaan penglihatan lalat 6 kali lebih besar dibandingkan manusia. Selain itu, mata lalat juga dapat mengindera frekuensi-frekuensi ultraviolet pada spektrum cahaya terlihat oleh manusia. Berdasarkan berbagai macam percobaan, dapat dibuktikan bahwa serangga terutama lalat rumah dapat mengenal dan memedakan jenis warna. Serangga dapat melihat sinar ultraviolet dengan jelas. (Dewi Nur, 2006).Kepekaan lalat rumah terhadap cahaya berada di antara rentang panjang gelombang $310 \mu \mathrm{m}$ dan $700 \mu \mathrm{m}$. Studi lainnya tentang fotoreseptor pada komponen mata lalat rumah menyebutkan terdapatnya 3 puncak kepekaan cahaya, yaitu pada panjang gelombang $490 \mu \mathrm{m}$ (biru/hijau), $570 \mu \mathrm{m}$ (kuning), dan pada rentang panjang gelombang ultraviolet yaitu 300-350 $\mu \mathrm{m}$ (Hanley, 2008).

Rumah Pemotongan Ayam (RPA) merupakan salah satu industri peternakan dimana dilakukan pemotongan ayam hidup dan mengolah menjadi karkas ayam siap konsumsi. Limbah padat rumah pemotongan ayam relatif lebih mudah ditangani dibanding dengan limbah cair. Dalam proses produksi rumah pemotongan ayam dihasilkan limbah cair yang berasal dari darah ayam, proses pencelupan, pencucian ayam dan peralatan produksi. (Moses Laksono, 2008). Aktivitas pemotongan ayam membawa dampak pencemaran bagi lingkungan dan kesehatan masyarakat sekitar. Dampak pencemaran tersebut dilihat dari 3 aspek. Aspek pertama yaitu aspek fisik, yaitu berupa air limbah cair dan limbah padat hasil pemotongan ayam yang menimbulkan bau tidak sedap. Aspek kedua yaitu aspek kimia yang berpotensi mencemari lingkungan. Aspek ketiga yaitu aspek biologi, yaitu adanya timbulan sampah terutama limbah padat menjadi tempat perindukan lalat. Dampak buruk yang dihasilkan oleh rumah pemotongan ayam yaitu jumlah populasi lalat yang meningkat yang dapat berdampak langsung kepada masyarakat yang bermukim disekitarnya, seperti yang kita ketahui bahwa lalat merupakan vektor penyebab penyebar penyakit yang banyak merugikan manusia. Lalat juga dapat tertarik dengan cahaya terutama cahaya yang menghasilkan sinar ultraviolet (UV).
Kondisi tersebut berdampak pada risiko cemaran mikroorganisme penyebab penyakit yang dibawa oleh lalat dengan mengontaminasi daging ayam yang dijual di RPA Bara Barayya Utara. Bila daging ayam yang dibeli konsumen dari RPA Bara Barayya Utara tidak dimasak dengan baik sebelum di konsumsi, maka resiko terjadinya penularan penyakit bersumber mikroorganisme patogen akan meningkat.Lalat pada umumnya tertarik pada bau-bauan busuk yang dihasilkan oleh limbah pemotongan ayam.

Berdasarkan penelitian diatas, peneliti tertarik untuk melakukan sebuah penelitian "Studi Variasi Warna Lampu Terhadap Alat Perekat Lalat Di Rumah Pemotongan Ayam" dengan menggunakan perangkap sederhana dengan variasi warna lampu tubular lamp yang di rangkaikan di atas tripleks yang berukuran $30 \times 30$ $\mathrm{cm}$ dan pada bagian alas tripleks diberi alat perekat lalat yang dilakukan di rumah pemotongan ayam.

\section{METODE PENELITIAN \\ Jenis, Lokasi, Dan Waktu Penelitian}

Adapun jenis penelitian ini bersifat eksprimen semu dengan melakukan pengamatan uji coba variasi warna lampu terhadap alat perekat lalat dengan jumlah lalat yang terperangkap pada alat. Adapun lokasi penelitian ini bertempat di Rumah Pemotongan Ayam (RPA) Jln. Muh. Yamin Kelurahan Bara Barayya Timur Kec. Makassar Kota Makassar. Waktu penelitian dilaksanakan pada bulan maret - bulan Austusus 2018.

\section{PROSEDUR PENELITIAN}

Hal yang dilaksanakan adalah menentukan lokasi untuk pemaparan alat. Kemudian persiapan alat seperti tripleks, rangkaian variasi warna lampu tubular lamp (biru, kuning dan hijau), alat perekat dan kabel sebaiknya tripleks yang digunakan disesuaikan dengan panjang lampu Tubular Lamp kemudian kabel sepanjang $150 \mathrm{~cm}$, buatlah 3 rangkaian untuk 3 warna lampu yang berbeda dengan jarak $50 \mathrm{~cm}$ tiap bola lampu. Pada bagian atas tripleks diletakkan rangkaian lampu tubular lamp berwarna biru, kuning dan hijau. Bagian alas tripleks diberi kertas perekat lalat. Alat digantung menggunakan tali diletakkan pada tempat yang mempunyai suhu dan kelembaban yang sama. Pemaparan dilakukan selama 2 jam pada pagi hari dan 2 jam pada sore hari. Lakukan pengamatan secara langsung dan hitung jumlah lalat yang terperangkap pada alat perekat lalat tersebut. 
Jurnal Sulolipu : Media Komunikasi Sivitas Akademika dan Masyarakat

Vol. 20 No.2 2020

e-issn : 2622-6960, p-issn : 0854-624X

\section{PENGUMPULAN DATA}

Data diperoleh dari hasil pengamatan langsung pada saat melakukan penelitian. Pencatatan dilakukan setiap kali pemaparan pada lampu tubular lamp dan pengumpulan data yang di kelompokkan menurut variasi warna lampu terhadap alat perekat lalat dengan jumlah lalat yang terperangkap, kemudian dihitung nilai persentase banyaknya lalat rumah yang terperangkap pada alat perekat. Adapun Data penunjang diproleh dari penelusuran kepustakaan berupa referensi hasil penelitian sebelumnya, jurnal, artikel.

\section{Analisa Data}

Hasil dari pengamatan dan pemaparan secara langsung yang didapatkan pada saat pelaksanaan eksprimen dilapangan yang disajikan dalam bentuk tabel berdasarkan jumlah lalat yang terperangkap dinilai dengan satuan ekor.

\section{HASIL}

1. Jumlah Lalat Yang Terperangkap Pada Alat Perekat Dengan Variasi Warna Lampu Di Pagi Hari

Berdasarkan hasil pemaparan yang dilakukan pada pagi hari didapatkan hasil yaitu:

Tabel 1. Jumlah Lalat Yang Terperangkap Pada Alat Perekat Dengan Variasi Warna Lampu Di Pagi Hari

\begin{tabular}{|c|c|c|c|c|c|c|}
\hline \multicolumn{2}{|c|}{$\begin{array}{r}\text { PemaparanKontrol } \\
\text { (Tanpa } \\
\text { Lampu) }\end{array}$} & \multicolumn{3}{|c|}{$\begin{array}{l}\text { Perlakuan } \\
\text { (ekor) }\end{array}$} & \multirow[t]{2}{*}{$\begin{array}{l}\text { Suhu } \\
\left({ }^{\circ} \mathrm{C}\right)\end{array}$} & \multirow[t]{2}{*}{$\begin{array}{l}\text { Kelembaban } \\
(\%)\end{array}$} \\
\hline & Ekor & \multicolumn{3}{|c|}{ BiruKuning Hijau } & & \\
\hline Hari ke-1 & 15 & 24 & 21 & 21 & 29,0 & 54 \\
\hline Hari ke-2 & 8 & 23 & 8 & 46 & 29,12 & 55 \\
\hline Hari ke-3 & 1 & 10 & 3 & 18 & 32,7 & 56 \\
\hline Hari ke-4 & 17 & 7 & 27 & 33 & 29,5 & 62 \\
\hline Rata-rata & 10 & 16 & 15 & 30 & \multicolumn{2}{|c|}{$30,08^{\circ} \mathrm{C} 56,75 \%$} \\
\hline
\end{tabular}

Sumber : Data primer , 2018
2. Jumlah Lalat Yang Terperangkap Pada Alat Perekat Dengan Variasi Warna Lampu Di Sore Hari

Tabel 2. Jumlah Lalat Yang Terperangkap Pada Alat Perekat Dengan Variasi Warna Lampu Di Sore Hari

\begin{tabular}{|c|c|c|c|c|c|c|}
\hline Pemapara & $\begin{array}{l}\text { Kontrol } \\
\text { (Tanpa }\end{array}$ & $\begin{array}{l}\text { Per } \\
\text { (ek }\end{array}$ & $\begin{array}{l}\text { akua } \\
\text { r) }\end{array}$ & & Suhu & Kelembaban \\
\hline & Ekor & Birl & Kur & $\mathrm{Hijau}$ & & \\
\hline Hari ke-1 & 16 & 26 & 26 & 43 & 35,52 & 44 \\
\hline Hari ke-2 & 4 & 14 & 18 & 49 & 37,7 & 39 \\
\hline Hari ke-3 & 5 & 26 & 16 & 31 & 39,2 & 33 \\
\hline Hari ke-4 & 0 & 20 & 1 & 21 & 36,6 & 42 \\
\hline Rata-rata & 6 & 22 & 15 & 36 & 37,25 & $39 \%$ \\
\hline
\end{tabular}

Sumber : Data primer, 2018

\section{Hasil Pengukuran Kepadatan Lalat Di RPA Pada Pagi Hari Menggunakan Flygrill}

Tabel 3. Hasil Pengukuran Kepadatan Lalat Di RPA Pada Pagi Hari Menggunakan Flygrill

\begin{tabular}{|c|c|c|c|}
\hline & & Suhu & Kelembaban \\
\hline Pengukuran & Jumlah Lalat & $\left({ }^{\circ} \mathrm{C}\right)$ & $(\%)$ \\
\hline Hari ke-1 & 9 & 26,4 & 67 \\
\hline Hari ke-2 & 6 & 28,5 & 62 \\
\hline Hari ke-3 & 3 & 27,6 & 63 \\
\hline Hari ke-4 & 4 & 29,3 & 64 \\
\hline Rata-Rata & 6 ekor & $27,95^{\circ} \mathrm{C}$ & $64 \%$ \\
\hline
\end{tabular}

\section{Hasil Pengukuran Kepadatan Lalat Di RPA Pada Sore Hari Menggunakan Flygrill}

Tabel 4 Hasil Pengukuran Kepadatan Lalat Di RPA Pada Sore Hari Menggunakan Flygrill

\begin{tabular}{|c|c|c|c|}
\hline Pengukuran & Jumlah Lala & t Suhu & Kelembaban \\
\hline & & $\left({ }^{\circ} \mathrm{C}\right)$ & $(\%)$ \\
\hline Hari ke-1 & 8 & 35,2 & 44 \\
\hline Hari ke-2 & 7 & 35,4 & 43 \\
\hline Hari ke-3 & 4 & 35,4 & 43 \\
\hline Hari ke-4 & 5 & 35,0 & 44 \\
\hline Rata-Rata & 6 ekor & $35,25^{\circ} \mathrm{C}$ & $43,5 \%$ \\
\hline
\end{tabular}

Sumber : Data primer , 2018 
Jurnal Sulolipu : Media Komunikasi Sivitas Akademika dan Masyarakat

Vol. 20 No.2 2020

e-issn : 2622-6960, p-issn : 0854-624X

\section{PEMBAHASAN}

Penelitian ini dilakukan sabagai salah satu upaya dalam menerapkan teknologi tepat guna bagi masyarakat dan solusi dalam dalam menghadapi permasalahan kesehatan lingkungan khsususnya pengendalian vektor (lalat) penyakit. Berdasarkan hasil penelitian yaitu "Studi Variasi Warna Lampu Terhadap Alat Perekat Lalat di Rumah Pemotongan Ayam " adalah sebagai berikut:

\section{Pemaparan Pada Alat Perekat dengan Variasi Warna Lampu di Pagi dan Sore} Hari.

Tempat pemotongan ayam yang terletak dekat dengan pemukiman penduduk, kondisi tempat pemotongan ayam yang terbuka dan kurang bersih dapat mengundang datangnya bahkan tempat perkembangbiakan lalat. Kepadatan lalat yang didapatkan dari hasil pengukuran selama penelitian berlangsung pada pagi dan sore hari di dapatkan hasil 6 ekor/block grill dan dikategorikan tinggi.

Berdasakan hasil pemaparan yang dilakukan pada pagi hari di dapatkan hasil yaitu pada hari ke-1 jumlah lalat yang paling banyak terperangkap di alat perekat dengan warna lampu biru sebanyak 24 ekor sedangkan terendah adalah kontrol sebanyak 15 ekor dengan suhu $29,0^{\circ} \mathrm{C}$ dan kelembaban $54 \%$. Pemaparan dilakukan di samping proses pemotongan ayam berlangsung dimana setiap lampunya berjarak $50 \mathrm{~cm}$ dan mempunyai suhu dan kelembaban yang sama.

Pada pemaparan hari ke-2 jumlah lalat yang paling banyak terperangkap dialat perekat lalat dengan warna lampu hijau yaitu sebanyak 46 ekor sedangkan yang terendah pada kontrol yaitu sebanyak 8 ekor dengan suhu $29,12^{\circ} \mathrm{C}$ dan kelembaban $55 \%$. Pemaparan pada hari ke-3 diperoleh hasil 18 ekor pada lampu warna hijau sedangkan yang terendah di kontrol tanpa lampu sebanyak 1 ekor dengan suhu $32,7^{\circ} \mathrm{C}$ dan kelembaban $56 \%$. Hal ini disebabkan karena adanya perbedaan waktu pemaparan yang dilakukan pada hari ke-3 dibandingkan dengan hari ke-1 dan ke-2 yang dilakukan lebih awal, sehingga suhu dan kelembabannya lebih tinggi. Adapun faktor lain yang mempengaruhi jumlah lalat yang terperangkap pada hari ke-3 yaitu dimana tidak ada terjadinya proses pemotongan ayam tetapi terdapat tumpukan sampah domestik dan kotoran ayam yang belum dibersihkan.
Pemaparan yang dilakukan pada hari ke-4 jumlah lalat yang paling banyak terperangkap di alat perekat lalat dengan warna lampu hijau yaitu sebanyak 33 ekor sedangkan yang terendah yaitu pada kontrol yaitu sebanyak 41 ekor dengan suhu $29,5^{\circ} \mathrm{C}$ dan kelembaban $62 \%$.

Hasil rata-rata yang didapatkan pada pemaparan yang dilakukan selama 4 hari dipagi hari di peroleh hasil yaitu dimana jumlah lalat yang paling banyak terperangkap pada lampu warna hijau dibandingkan warna lampu biru dan kuning. Nilai rata-rata pada

variasi lampu warna hijau yaitu sebanyak 30 ekor dikategorikan sangat tiggi, tertinggi kedua yaitu variasi lampu biru sebanyak 16 ekor dikategorikan tinggi, tertinggi ke tiga pada yaitu variasi warna lampu kuning sebanyak 15 ekor dikategorikan tinggi dan yang paling terendah pada kontrol yaitu sebanyak 10 ekor dikategorikan tinggi dengan suhu $30,08^{\circ} \mathrm{C}$ dan kelembaban $56,75 \%$.

Pada pemaparan yang dilakukan pada sore hari didapatkan hasil yaitu pada hari ke-1 jumlah lalat yang paling tinggi yaitu pada alat perekat lalat dengan warna lampu hijau yaitu sebanyak 43 ekor dan terendah pada kontrol yaitu sebanyak 16 ekor dengan suhu $35,52^{\circ} \mathrm{C}$ dan kelembaban $44 \%$.

Pemaparan pada hari ke-2 sampai dengan hari ke-4 jumlah lalat yang paling tinggi yaitu pada alat perekat dengan warna lampu hijau yaitu 49 ekor, 31 ekor dan 21 ekor, sedangkan jumlah lalat yang terendah yaitu pada alat perekat kontrol sebanyak 4 ekor, 5 ekor, dan pada hari ke-4 tidak ada lalat yang terperangkap pada alat perekat tersebut.

Nilai rata-rata yang di dapatkan pada pemaparan yang dilakukan selama 4 hari pada sore hari diperoleh hasil jumlah lalat yang paling banyak terperangkap pada alat perekat dengan warna lampu hijau yaitu 36 ekor (sangat tinggi) sedangkan jumlah lalat yang terperangkap pada alat perekat lalat dengan penambahan warna lampu biru dan kuning yaitu sebanyak 26 ekor (sangat tinggi) dan 15 ekor (tinggi). Jumlah lalat yang paling rendah yaitu pada alat perekat kontrol yaitu sebanyak 6 ekor (tinggi) dengan suhu $37,25^{\circ} \mathrm{C}$ dan kelembaban $39 \%$.

Dari pemaparan yang telah dilakukan di rumah pemotongan ayam dan berlangsung selama 4 hari pada pagi dan sore hari telah didapatkan hasil yaitu jumlah lalat yang paling banyak terperangkap pada alat perekat dengan penambahan warna lampu hijau dibandingkan dengan penambahan warna 
lampu biru dan kuning. Hal ini disebabkan karena tingginya warna gelombang yang di pancarkan oleh warna hijau yaitu $500 \mu \mathrm{m}$. Kisaran kepekaan mata lalat antara $245-600$ $\mu \mathrm{m}$ (Dewi 2006), maka warna hijau berada di tengah-tengah warna kuning dan biru pada panjang gelombang kepekaan lalat tersebut.

Alat perekat warna biru memperoleh hasil tertinggi kedua, lampu warna biru juga memancarkan sinar ultraviolet yang dapat memikat perhatian lalat. Alat perekat dengan penambahan warna kuning memperoleh hasil yang paling sedikit memerangkap lalat karena lampu warna kuning yang digunakan memiliki cahaya yang redup/ tidak lebih terang dari warna lampu hijau dan biru, walaupun warna kuning berada pada panjang gelombang yang disukai lalat. Untuk alat perekat kontrol tanpa lampu memperoleh hasil terendah daripada alat perekat dengan penambahan variasi warna lampu. Hal tersebut menunjukkan bahwa pemberian warna lampu dengan warna yang disukai lalat dapat menambah jumlah lalat yang terperangkap.

Kepekaan dan penyebaran lalat sangat di pengaruhi oleh reaksi terhadap cahaya, suhu dan kelembaban udara, serta warna dan permukaan tempat. Lalat memiliki sifat fototrofik (tertarik pada cahaya) sehingga beraktivitas pada siang hari dan beristirahat pada malam hari (Rozendaal 1997 dalam Sayono 2010).

Dari pemaparan yang dilakukan pada pagi dan sore hari jumlah lalat yang paling banyak terperangkap yaitu pada sore hari hal ini dikarenakan oleh padatnya pemotongan ayam yang berlangsung pada sore hari di bandingkan pada pagi hari sehingga memicu datangnya lalat akibat bau yang di timbulkan. Proses pemotongan ayam yang pada dapat menghasilkan bulu-bulu ayam, darah maupun usus ayam yang menimbulkan bau. Kandang ayam yang kurang bersih dimana terdapat kotoran ayam yang dapat menjadi tempat perkembangbiakan lalat. Selain itu, suhu dan kelembaban juga mempengaruhi kepadatan lalat yaitu lalat aktif pada suhu optimum 20$25^{\circ} \mathrm{C}$, hinggap pada suhu $35-40^{\circ} \mathrm{C}$ dan mati pada suhu dibawah $10^{\circ} \mathrm{C}$ dan diatas $40^{\circ} \mathrm{C}$ sedangkan pada kelembaban yang optimal dimiliki lalat agar dapat beraktivitas adalah $50-90 \%$.

Lalat yang paling banyak terperangkap adalah lalat rumah dan lalat daging. Lalat rumah memiliki ciri-ciri tubuh berwarna coklat kehitam-hitaman, pada thorax terdapat 4 garis hitam dan sayap berbentuk sudut sedangkan lalat daging berukuran lebih besar dari lalat rumah terdapat bintik merah pada ujung badan. (Singgih H, 2006).

Tingginya tingkat kepadatan lalat yang ada dilokasi penelitian dapat berdampak buruk terhadap masyarakat yang ada disekitar tempat pemotongan. Lalat sebagai vektor penyebaran penyakit seperti diare, typus, disentri dan cholera. Untuk mengurangi tingkat kepadatan lalat maka dapat dilakukan cara yaitu membersihkan kandang ayam setiap hari setelah selesai melakukan pemotongan, menyiapkan tempat sampah yang kedap air, membedahkan sampah basah dan sampah kering, membuat saluran pembuangan air limbah (SPAL) yang tertutup, memasang alat perangkap lalat dengan alat perekat lalat dengan penambahan variasi warna lampu hijau untuk meminimalisir tingkat kepadatan lalat yang ada di tempat pemotongan.

\section{Tingkat Kepadatan Lalat Menggunakan Flygrill Pada Pagi dan Sore Hari}

Berdasarkan hasil yang telah diperoleh mengenai pengukuran kepadatan lalat menggunakan flygrill di rumah pemotongan ayam Kelurahan Bara-Barayya Timur yang dilakukan pada pagi hari dengan gabungan hasil rata-rata dari titik 1, 2 dan 3 yang dilakukan di hari ke-1 diperoleh hasil yaitu 9 ekor/block grill dengan suhu $26,4^{\circ} \mathrm{C}$ dan kelembaban $67 \%$, sedangkan pada pengukuran hari ke-2 diperoleh hasil yaitu 6 ekor/block grill dengan suhu $28,5^{\circ} \mathrm{C}$ dan kelembaban $62 \%$. Tingkat kepadatan pada hari ke-1 dan hari ke-2 dikategorikan tinggi . Pada pengukuran hari ke-3 diperoleh hasil yaitu 3 ekor/block grill dengan suhu $27,6^{\circ} \mathrm{C}$ dan kelembaban 63\%, sedangkan padapengukuran hari ke-4 diperoleh hasil yaitu 4 ekor/block grill dengan suhu $29,4^{\circ} \mathrm{C}$ dan kelembaban $64 \%$. Tingkat kepadatan dikategorikan sedang.

Hasil rata-rata dari pengukuran pada hari ke-1 sampai dengan hari ke-4 yang dilakukan pada pagi hari diperoleh hasil 6 ekor/blockgrill dengan suhu $27,95^{\circ} \mathrm{C}$ dan kelembaban $64 \%$, tingkat kepadatan lalat dikatakan tinggi.

Pengukuran lalat juga dilakukan pada sore hari dimana pada hari ke-1 jumlah kepadatan lalat diperoleh hasil sebanyak 9 ekor/block grill dengan suhu $35,5^{\circ} \mathrm{C}$ dan kelembaban $44 \%$ sedangkan pengukuran pada hari ke-2 diperoleh hasil 7 ekor/blockgrill dengan suhu $35,4^{\circ} \mathrm{C}$ dan kelembaban $43 \%$, sedangkan pada pengukuran pada hari ke-2 diperoleh hasil 7 ekor/blockgrill dengan suhu 
$35,4^{\circ} \mathrm{C}$ dan kelembaban $43 \%$, tingkat kepadatan dikategorikan tinggi.

Pada pengukuran hari ke-3 diperoleh hasil sebanyak 4 ekor/block grill dengan suhu $35,4^{\circ} \mathrm{C}$ dan kelembaban $43 \%$, sedangkan pengukuran pada hari ke-4 diperoleh hasil yaitu 5 ekor/block grill dengan suhu $35,0^{\circ} \mathrm{C}$ dan kelembaban $44 \%$, tingkat kepadatan dikategorikan sedang.

Hasil rata-rata dari pengukuran pada hari ke-1 sampai dengan hari ke-4 yang dilakukan pada sore hari diperoleh hasil 6 ekor/blockgrill dengan suhu $35,25^{\circ} \mathrm{C}$ dan kelembaban $43,5 \%$, tingkat kepadatan lalat di kategorikan tinggi (Permenkes No. 50 Tahun 2017).

Dari penjelasan diatas hasil rata-rata pengukuran lalat yang dilakukan pada pagi dan sore hari diperoleh hasil yaitu 6 ekor/blockgrill yang dikategorikan tinggi, hal ini disebabkan oleh kondisi sanitasi di rumah pemotongan ayam tidak memenuhi syarat karena masih adanya limbah sisa pemotongan ayam yang belum diangkut seperti bulu-bulu ayam dan usus ayam yang menimbulkan bau, saluran pembuangan air limbah yang terbuka serta kondisi tempat sampah domestik yang tidak mempunyai penutup dan kondisi lantai yang lembab.

Lalat menyukai tempat yang lebih basah seperti kotoran binatang dan kotoran yang menumpuk secara kumulatif (dikandang). Tempat perindukan lalat yang paling utama adalah pada kotoran hewan yang lembab dan masih baru. Lalat lebih senang berkembang biak didalam kotoran hewan ternak terutama kotoran ayam $(\mathrm{H}$. Arroyo, 2011).

Tingkat kepadatan lalat yang ada di rumah pemotongan ayam di pengaruhi oleh faktor lingkungan yang sangat mendukung perkembangbiakan lalat tersebut. Faktor lingkungan yang dapat mempengaruhi tingkat kepadatan lalat antara lain keberadaan sumber makanan bagi lalat, lingkungan yang kotor, keadaan suhu dan kelembaban udara yang sangat mendukung lalat berkembang biak dengan suhu optimum lalat beraktivitas yaitu pada suhu $20-25^{\circ} \mathrm{C}$, hinggap pada suhu $35-40^{\circ} \mathrm{C}$ dan mati pada suhu dibawah $10^{\circ} \mathrm{C}$ atau diatas $40^{\circ} \mathrm{C}$ sedangkan pada kelembaban yang optimal dimiliki lalat agar dapat beraktivitas adalah 50-90\%. (Rozendaal 1997 dalam Sayono 2010).

\section{Kelebihan Dan Kelemahan Penelitian}

a. Alat yang digunakan relatif ekonomis dan proses pembuatannya mudah dilakukan dimana bahan yang digunakan pada perangkap ini dapat ditemukan di sekitar masyarakat.

b. Penggunaan variasi lampu dengan alat perekat ini dapat digunakan untuk menekan tingkat populasi vektor seperti menurunkan tingkat kepadatan lalat.

c. Penggunaan alat pengendalian lalat ini hanya bisa digunakan jika terhubung dengan aliran listrik.

\section{KESIMPULAN DAN SARAN}

Berdasarkan hasil penelitian yang telah dilakukan di Rumah Pemotongan Ayam Kelurahan Bara-Barayya Kota Makassar, maka dapat ditarik kesimpulan bahwa jumlah lalat yang terperangkap pada lampu warna biru di pagi hari dikategorikan tinggi yaitu 16 ekor sedangkan pada sore hari dikategorikan sangat tinggi yaitu 22 ekor. Pada lampu warna kuning di pagi hari dikategorikan tinggi yaitu tinggi 15 ekor sedangkan pada sore hari dikategorikan sangat tinggi yaitu 22 ekor adapun pada lampu warna hijau di pagi hari dikategorikan sangat tinggi yaitu 30 ekor sedangkan pada sore hari dikategorikan sangat tinggi yaitu 36 ekor sedangkan pada kontrol tanpa lampu di pagi hari dikategorikan tinggi yaitu 10 ekor sedangkan pada sore hari dikategorikan tinggi yaitu 6 ekor.

\section{DAFTAR PUSTAKA}

Chandra B. Pengantar Kesehatan Lingkungan. Jakarta: Buku Kedokteran EGC; 2007.

Sembel DT. Entomologi Kedokteran. Edisi I. Yogyakarta: Penerbit Andi; 2009

Chapman. Serangga. Yogyakarta: Kanisius; 2001.

Putra NS. Serangga di Sekitar Kita. Yogyakarta: Kanisius; 1994.

Sucipto CD. Vektor Penyakit Tropis. Yogyakarta:Gosyen Publishing; 2011.

Manalu M, Marsaulina I, Ashar T. Hubungan tingkat kotak yang sama yaitu putih bening. Kesulitan kepadatan lalat (Musca domestica) dengan kejadian diare pada balita di sekitar tempat 
Jurnal Sulolipu : Media Komunikasi Sivitas Akademika dan Masyarakat

Vol. 20 No.2 2020

e-issn : 2622-6960, p-issn : 0854-624X

pembuangan akhir sampah Namo Bintang Deli Serdang tahun 2012. Jurnal Kesehatan Lingkungan dan KeselamataKerja. 2013; 2 (3): 1-10.

Nurcahyo EM. Memberantas Binatang Pengganggu di Lingkungan Rumah. Jakarta: Penebar Swadaya; 2005

Winarno FG. Hama Gudang dan Teknik Pemberantasannya. Bogor: MBRIO PRESS; 2006.

Anonim,2012.(Online)http://amp.kompas.com/sains/read/2012/04/10/05200358/Lampu.TL.Kendalika. hama.dan.ramah.lingkungan. Diakses pada 11 Desember 2017

Ardiansyah. 2015. Adaptasi Masyarakat Terhadap Keberadaan Rumah Potong Ayam Di Kelurahan Bara-Baraya Timur Kecamatan Makassar. Makassar : Jurusan Sosial Ekonomi Peternakan Universitas Hasanuddin Makassar (Skripsi), (Online) http://repository.unhas.ac.id/handle. Diakses pada 09 Desember 2017.

Dewi Nur Jannah. 2006. Perbedaan Kepadatan Lalat pada Berbagai Warna Fly Grill. Surabaya: Fakultas Kesehatan Masyarakat Universitas Airlangga Surabaya (Skripsi), (Online) http://lib.unair.ac.id. Diakses 26 November 2017.

Dinas Kesehatan Provinsi Sulawesi Selatan. 2014. Profil Provinsi Sulawesi Selatan Tahun 2014. Makassar. (Online) http://dinkes.sulselprov.go.id. Di kses pada 11 Desember 2017

Endang Puji Astuti dan Firda Yanuar Pradani. 2010. Pertumbuhan dan Reproduksi Lalat

Musca domestica pada Berbagai Media Perkembangbiakan. Loka Litbang P2B2 Ciamis. (Online). http://ejournal.litbang.depkes.go.id/index.php/aspirator/article/view/2938). Diakses pada tanggal 09 Desember 2017.

Fitriana Puspitarani, dkk. 2017. Penerapan Lampu Ultraviolet Pada Alat Perangkap Lalat Terhadap Jumlah Lalt rumah Yang Terperangkap. Semarang: Epidemiologi dan Biostatistika, Jurusan ilmu Kesehatan Masyarakat, Fakultas IImu Keolahragaan, Universitas Negeri Semarang. (online) http://journal.unnes.ac.id/sju/index.php/higea. Diakses 07 Desember 2017.

Habib Alfa Eni K, 2013. Studi Deskriftif Tingkat Kepadatan Lalat Di Permukiman Sekitar Rumah Pemotongan Unggas (RPU) Penggaron Kelurahan Penggaron Kudul Kecamatan Pedurungan Kota Semarang. Semarang (online), http://journal.unnrs.ac.id/sju/index.php/ujph. Diakses pada 07 Desember 2017.

Hanley , M. E., dkk. 2008. Luring Houseflies (Musca Domestica) to Traps. Medical and Veterinary Entomology Journal. (Online) http://www.ncbi.nml.nih.gov. Diakses 12 Desember 2017

Moses Laksono. 2008. Peningkatan Produktivitas dan Kinerja Kerja Lingkungan dengan Pendekatan Green Productivity pada Rumah Pemotongan Ayam, (online), http://www.academia.edu/download/27531144/3846-moses-ie

20080811_peningkatan_produktivitas_dan_kinerja_lingkungan_moses_mera.pdf, Diakses 05 Desember 2017.

Nartika Emelia. 2016. Sanitasi Dasar dengan Tingkat Kepadatan Lalat di Rumah Makan

Pasar Pinasungkulan Karombasan Kota Manado. Manado. (online), https://ejournalhealth.com/index.php/ikmas/article/view/90. Diakses 07 Desember 2017.

Republik Indonesia, 2017. Peraturan Menteri Kesehatan RI No. 50 Tahun 2017 tentang Standar Baku Mutu Kesehatan Lingkungan dan Persyaratan Kesehatan untuk Vektor dan Binatang Pembawa Penyakit Serta Pengendaliannya. (Online)http:// hukor.kemkes.go.id. Diakses 02 Juni 2018

Robertus Dita P, dkk. 2014. Pengaruh Variasi Warna Lampu Terhadap Alat Perekat Lalat Dengan Jumlah Lalat Rumah (Musca Domestica) Yang Terperangkap. (Online) http://ejournal.litbang.depkes.go.id. Diakses pada 02 Desember 2017. 
Jurnal Sulolipu : Media Komunikasi Sivitas Akademika dan Masyarakat

Vol. 20 No.2 2020

e-issn : 2622-6960, p-issn : 0854-624X

Sayono. 2004. Pengaruh Posisi Dan Warna Impregnated Cordterhadap Jumlah Lalat Yang Terperangkap. (Online). Fakultas Kesehatan Masyarakat Universitas Muhammadiyah Semarang. (http:// jurnal.unimus.ac.id ıHome > 2004). Diakses 15 Desember 2017

Singgih H, dkk. 2006. Hama Permukiman Indonesia Pengenalan, Biologi, dan Pengendalian. Bogor : Unit Kajian Pengendalian Hama Permukiman Fakultas

Suarni. 2004. Hubungan Warna Wadah Sampah dengan Kepadatan Lalat Rumah (Musca Domestica) di Pasar Hartaco Kel. Paranng Tambung Kec. Tamalate Kota Makassar. Makassar: Prodi D.III Jurusan Kesehatan Lingkungan Poltekkes Makassar (KTI Tidak Diterbitkan).

Syamsuddin S, dkk. 2017. Modul Pest Control. Makassar: Jurusan Kesehatan Lingkungan Politeknik Kesehatan Makassar. 